\title{
HACIA LA RESPONSABILIDAD DE PROTEGER. BASES JURÍDICAS PARA UNA RESPUESTA COLECTIVA ANTE CRISIS HUMANITARIAS
}

\author{
Pablo César ReVILla MonTOYA*
}

RESUMEN: El fin de la Guerra Fría ha significado un reacomodo en el sistema internacional, lo cual trajo como consecuencia la aparición de conflictos interétnicos que conllevaron al genocidio o limpieza étnica en determinados lugares del mundo. Ante esta situación, aparece la doctrina de la "responsabilidad de proteger" como alternativa a estas prácticas inhumanas. En esta investigación analizaremos las bases jurídicas para una respuesta colectiva ante crisis humanitarias con base en esta novedosa doctrina.

ABSTRACT: The end of the Cold War has signified an adjustment in the international system bringing as consequence the sprouting of interracial conflicts that involved to the genocide or ethnic cleansing in determined places of the world. On behalf of, the doctrine of the "responsibility to protect" appears as an alternative to these inhuman practices. In this research we will analyze the juridical bases for a collective answer for a humanitarian crisis in according to this new doctrine.

RÉSUMÉ: La fin de la Guerre Froide a signifié un réajustement du système international dont l'une des conséquences fut la déflagration de conflits interethniques ayant par endroit mené jusqu'au génocide ou l'épuration ethnique. Face à cette situation apparaît la doctrine de la "responsabilité de protéger" comme alternative à ces pratiques inhumaines. Le présent travail a pour but analyser les bases juridiques d'une réponse collective aux crises humanitaires selon les préceptes particuliers de la doctrine susmentionnée.

* Licenciado en derecho, miembro investigador del Taller de Derecho Internacional de la Facultad de Derecho de la Universidad Nacional Mayor de San Marcos de Lima. 
SUMARIO: I. Introducción. II. Surgimiento de la idea de la "responsabilidad de proteger" a las víctimas de las violaciones del ius cogens. III. Aspectos doctrinales de la "responsabilidad de proteger" a las víctimas de las violaciones del ius cogens. IV. Fundamentos jurídicos de la "responsabilidad de proteger" a las víctimas de las violaciones del ius cogens. V. Elementos de la "responsabilidad de proteger" a las víctimas de las violaciones del ius cogens. VI. Los responsables de proteger a las víctimas de las violaciones del ius cogens. VII. La "responsabilidad de proteger" a las víctimas de las violaciones del ius cogens y la intervención militar. VIII. Conclusiones.

\section{INTRODUCCIÓN}

La responsabilidad de proteger es un tema novedoso, pero que todavía no encuentra unanimidad en la doctrina del derecho internacional, a pesar de ello, creemos conveniente acogernos a los planteamientos de esta novísima doctrina como lege ferenda.

Teniendo en cuenta que antes de los atentados terroristas del 11 de septiembre del 2001 (11-S), la intervención por motivos humanitarios fue tal vez el tema más controvertido de la agenda internacional, la responsabilidad de proteger tuvo su aliciente en los discursos pronunciados por el secretario general de las Naciones Unidas Kofi Annan con ocasión del inicio de los periodos de sesiones de la Asamblea General de las Naciones Unidas de septiembre de 1990 y la Asamblea del Milenio de 2000 en los que hizo un llamamiento a la comunidad internacional para llegar a un consenso sobre la intervención humanitaria.

Sin embargo, la situación política mundial cambió a causa del unilateralismo estadounidense consecuencia del 11-S. En este trabajo buscaremos reavivar la discusión sobre la intervención humanitaria, pero desde la perspectiva de la responsabilidad de proteger.

\section{SURGIMIENTO DE LA IDEA DE LA "RESPONSABILIDAD DE PROTEGER" A LAS VÍCTIMAS DE LAS VIOLACIONES DEL IUS COGENS}

El 24 de marzo de 1999, la Organización del Tratado del Atlántico Norte (OTAN) intervino militarmente en Kosovo respondiendo a la crisis 
humanitaria y a la política de "limpieza étnica" del régimen del entonces presidente de Yugoslavia Slodoban Milosevic. A pesar de que la OTAN invocó motivos humanitarios, no tuvo la anuencia del Consejo de Seguridad de la ONU.

En ese contexto, el 20 de septiembre de 1999, Kofi Annan pronunció su famoso discurso de apertura del 54o. periodo de sesiones de la Asamblea General de la ONU, en el que expuso el dilema de la intervención humanitaria de la siguiente manera:

Por un lado, la cuestión de la legitimidad de la acción tomada por una organización regional sin una autorización de la ONU; y por otro lado, el imperativo universalmente reconocido de detener eficientemente las violaciones graves y sistemáticas de los derechos humanos con graves consecuencias humanitarias. La ineficacia de la comunidad internacional en el caso Kosovo para conciliar estos dos obligatorios intereses equitativamente fue una tragedia. Esto ha revelado el principal desafío del Consejo de Seguridad y de las Naciones Unidas como un todo en el próximo siglo: forjar una unión detrás del principio de que las infracciones masivas y sistemáticas de los derechos humanos - donde puedan tener lugar - no deberían ser permitidas... A ésos para los que la amenaza más grande para el futuro del orden internacional es el uso de la fuerza en ausencia de un mandato del Consejo de Seguridad, uno podría preguntar - no en el contexto de Kosovo- en el contexto de Ruanda: si en esos días y horas oscuras que acabaron en el genocidio, una coalición de Estados hubiera estado preparada para actuar en la defensa de la población tutsi, pero no reciben una rápida autorización del consejo, ¿tal coalición debería haber permanecido aparte y permitido que el horror se desarrollara? ${ }^{1}$

Finalmente, Kofi Annan dijo que: "si los Estados empeñados en el comportamiento delictivo saben que las fronteras no son absolutas; si saben que el Consejo de Seguridad tomará acción para detener crímenes contra la humanidad, entonces no se embarcarán en tal curso de acción a la expectativa de la impunidad soberana". ${ }^{2}$

1 Annan, Kofi, Secretary-General Presents His Annual Report to General Assembly, transcripción del discurso de apertura del Quincuagésimo Cuarto Periodo de Sesiones de la Asamblea General de las Naciones Unidas, 20 de septiembre de 1999, Press Release núm. SG/SM/7136/GA/9596, http://www.un.org/News/Press/docs/1999/ 19990920.sgsm7136.html.

2 Idem. 
Estas afirmaciones demostraron que las ideas humanitarias no sólo se habían extendido por organizaciones como la $\mathrm{OSCE}^{3}$ y la política exterior ocasional de líderes occidentales, sino también por las Naciones Unidas, descrita como "el último bastión de la soberanía nacional"4 por el antiguo vicesecretario general, Brian Urquhart. ${ }^{5}$

Para abril de 2000 se hizo público el Informe del Milenio, preparado por Kofi Annan, titulado Nosotros los Pueblos: el Papel de las Naciones Unidas en el siglo XXI, en el que hace un llamado a los Estados a comprometerse con un plan de acción para terminar con la pobreza y la desigualdad, mejorando la educación, reduciendo el VIH-SIDA, resguardando el medioambiente y protegiendo a los pueblos de los conflictos mortales y la violencia. El informe constituyó la base de la Declaración del Milenio asumida por los jefes de Estado y de gobierno en la Cumbre del Milenio de septiembre de 2000.

En dicho informe, el secretario general de la ONU expuso las siguientes ideas sobre la intervención humanitaria:

En mi discurso a la Asamblea General el pasado septiembre, pedí a los Estados miembros a unirse en la persecución de políticas más efectivas para detener el asesinato organizado de masas y las violaciones atroces de los derechos humanos. Aunque enfaticé que la intervención comprendía un amplio continuo de respuestas, desde la diplomacia hasta la acción armada, ésta fue aquella opción que generó la mayor de las controversias en el debate que siguió.

3 La Organización para la Seguridad y Cooperación en Europa (OSCE), tiene su antecedente en la Conferencia sobre la Seguridad y la Cooperación en Europa (CSCE) celebrada en Helsinki en 1975. Conformada por 55 Estados de Europa. incluyendo la Federación Rusa y todos los países de la Unión Europea, Asia Central y América del Norte (Canadá y Estados Unidos de América). Durante la Cumbre de Budapest, celebrada el 5 y 6 de diciembre de 1994, se decidió cambiar el nombre CSCE por el de OSCE.

4 Véase Stanley Foundation, Global Governance: Defining the United Nations, Leadership Role, Adare, County Limerick, Ireland, Stanley Foundation, 13-18 de junio de 1999 , p. 23.

5 Weiss, Thomas, "The Politics of Humanitarian Ideas", en varios autores, Contemporary Issues in the International Relations of the Developing World, Oxford, Oxford Policy Institute-Oxford Centre for International Studies, Seminar Series, Hilary Term 2000 Week Eight, http://www.opi.org.uk/pdf/HTOOWEEK_8_sent.pdf?opisid=25c9fd 03d861426086c222029f1a7ec2. 
Algunas críticas se referían a que el concepto de "intervención humanitaria" podría llegar a ser una cubierta para la interferencia injustificada en los asuntos internos de estados soberanos. Otros sentían que esto podría alentar movimientos separatistas para provocar deliberadamente a los gobiernos a cometer flagrantes violaciones de derechos humanos para provocar intervenciones externas que ayudarían su causa. Aún otros notaron que hay poca regularidad en la práctica de la intervención, debido a sus dificultades inherentes y costos tanto como intereses nacionales percibidos - excepto que los Estados débiles son mucho más probables de ser sujetos a la intervención que intervenga en unas-.

Reconozco tanto la fuerza como la importancia de estos argumentos. Acepto también que los principios de de soberanía y no intervención ofrecen la protección esencial a los Estados pequeños y débiles. Pero a los críticos yo les haría esta pregunta: si la intervención humanitaria es, en realidad, un ataque inaceptable a la soberanía, ¿cómo deberíamos responder a situaciones como las de Rwanda o Srebrenica y a las violaciones graves y sistemáticas de los derechos humanos que transgreden todos los principios de nuestra humanidad común? [enfatizado por nosotros]. ${ }^{6}$

El gobierno de Canadá respondió a este llamamiento del secretario general, convocando a una Comisión Internacional sobre Intervención y Soberanía de los Estados (CIISE), ${ }^{7}$ cuya creación fue anunciada por el entonces primer ministro de Canadá, Jean Cherétien, en la Cumbre del Milenio de las Naciones Unidas en septiembre de 2000.

A esta comisión se le solicitó que dilucidara las diversas cuestiones de tipo jurídico, moral, operacional y político incluidas en el debate, así como también que recabara en todo el mundo la mayor variedad posible de opiniones y que preparara un informe que ayudara al secretario general de las Naciones Unidas y a las demás partes interesadas a encontrar nuevos puntos de coincidencia ${ }^{8}$ en relación a la intervención y la soberanía de los Estados.

6 A/54/2000, "We the peoples: the role of the United Nations in the twenty-first century", Report of the Secretary-General, Fifty-Fourth session, Agenda item 49 (b), The Millennium Assembly of the United Nations, 27 de marzo de 2000, p. 35.

7 La Comisión Internacional sobre Intervención y Soberanía de los Estados publicó su informe The Responsibility to Protect, en diciembre de 2001.

8 Véase CIISE, The Responsibility to Protect, diciembre de 2001, pp. VII y VIII, http://www.iciss.ca/pdf/Spanish-report.pdf. 
La CIISE tuvo como copresidentes a Gareth Evans, presidente del International Crisis Group ${ }^{9}$ y ex ministro de Relaciones Exteriores de Australia, y al argelino Mohamed Sahnoun, asesor especial del secretario general de las Naciones Unidas. ${ }^{10}$

La CIISE presentó su informe ante la Asamblea General de las Naciones Unidas en diciembre de 2001, sin embargo, los atentados terroristas del 11-S ya habían cambiado la agenda internacional, cuya prioridad era ahora la lucha contra el terrorismo.

\section{Informe del Grupo de Alto Nivel sobre las Amenazas, los Desafios y el Cambio. Un Mundo más Seguro: la Responsabilidad que Compartimos (2 de diciembre de 2004)}

El secretario general de las Naciones Unidas, Koffi Annan, en la sesión inaugural del quincuagésimo octavo periodo de sesiones de la Asamblea General (septiembre de 2003) anunció su intención de crear un Grupo de Alto Nivel sobre las Amenazas, los Desafíos y el Cambio. Meses después informó ${ }^{11}$ al presidente de la Asamblea General de la ONU la creación de dicho grupo.

El Grupo de Alto Nivel tenía el siguiente mandato: ${ }^{12}$

9 El International Crisis Group es una organización no gubernamental cuya misión es prevenir y resolver conflictos a través del análisis de campo y la defensa de alto nivel. Su página web es la siguiente: http://www.crisisgroup.org/.

10 Adicionalmente se creó un equipo de investigación, dirigido conjuntamente por el estadounidense Thomas G. Weiss, catedrático y presidente del Graduate Center de la Universidad de Nueva York (CUNY), y por el zimbabwense Stanlake J. T. M. Samkange, redactor de discursos del ex secretario general de las Naciones Unidas Boutros Boutros-Ghali. Weiss fue el principal encargado de preparar los artículos de investigación, mientras que Stanlake Samkange se encargó de la relatoría, ayudando a la CIISE a redactar su informe.

11 UN. Doc. A/58/612, Carta del 3 de noviembre de 2003 dirigida al presidente de la Asamblea General por el secretario general, Quincuagésimo Octavo Periodo de Sesiones, tema 10 del programa: Memoria del Secretario General sobre la Labor de la Asamblea, 28 de noviembre de 2003. "Este Grupo de Alto Nivel debía encargarse de examinar las principales amenazas y desafíos que hace frente al mundo en la vasta esfera de la paz y la seguridad, incluidas las cuestiones económicas y sociales en la medida en que se relacionan con la paz y la seguridad, y hacer recomendaciones respecto de los elementos de una respuesta colectiva" (véase la carta citada).

12 UN. Doc. A/59/565, "Un mundo más seguro: la responsabilidad que compartimos", Informe del Grupo de Alto Nivel sobre las Amenazas, los Desafíos y el Cambio, Quincuagésimo Noveno Periodo de Sesiones, tema 55: Seguimiento de los 
a) Examinará las amenazas en el mundo de hoy y hará un análisis de los futuros desafíos a la paz y la seguridad internacionales. Por más que pueda seguir habiendo distintas ideas acerca de la importancia relativa de las diversas amenazas a que hace frente un determinado Estado miembro, es importante encontrar un equilibrio adecuado en el plano mundial y también es importante entender las conexiones que hay entre distintas amenazas;

b) Indicará claramente la contribución que puede hacer la acción colectiva para superar esos problemas;

c) Recomendará los cambios necesarios para asegurar una acción colectiva eficaz procediendo, entre otras cosas, a un estudio de los principales órganos de las Naciones Unidas.

El informe Un Mundo más Seguro: la Responsabilidad que Compartimos, se divide en cuatro partes, en varias de las cuales asume la posición tomada por la CIISE en relación a la "responsabilidad de proteger".

La primera parte del informe, titulada "Hacia un nuevo consenso en materia de seguridad" se explica que:

Al suscribir la Carta de las Naciones Unidas, los Estados no sólo se benefician de los privilegios de la soberanía, sino también asumen sus responsabilidades. Cualesquiera hayan sido las percepciones prevalecientes cuando el concepto de la soberanía estatal surgió tras la Paz de Westfalia, actualmente dicho concepto conlleva claramente la obligación de los Estados de proteger el bienestar de su población y de cumplir sus obligaciones con la comunidad internacional en general [enfatizado por nosotros]. Pero la historia nos enseña claramente que no puede darse por sentado que todos los Estados podrán o querrán siempre cumplir las obligaciones que les incumben en relación con su propia población y no causar daño a sus vecinos. $Y$ en tales circunstancias los principios de la seguridad colectiva significan que parte de esa obligación debe ser asumida por la comunidad internacional, actuando de conformidad con la Carta de las Naciones Unidas y la Declaración Universal de Derechos Humanos para crear la capacidad o proporcionar la protección necesarias, según el caso. ${ }^{13}$

Entendemos, entonces, que para el Grupo de Alto Nivel los Estados deben asumir su soberanía con responsabilidad, no sólo basándose en la

Resultados de la Cumbre del Milenio, 2 de diciembre de 20004, anexo II, párr. 2 del mandato, p. 104. Puede ser consultado en castellano en: http://www.un.org/spanish/ secureworld/.

13 UN. Doc. A/59/565..., cit., nota anterior, párr. 29. 
autonomía (soberanía interna), sino también en la protección de su propia población y la de todos los Estados en general, de conformidad con la Carta de las Naciones Unidas y la Declaración Universal de Derechos Humanos.

Sin embargo, algunos Estados no tienen la capacidad como para poder asumir su soberanía de manera responsable, por lo que según el informe, "para quienes estén en condiciones de ayudar a otros a mejorar esa capacidad, esta tarea debe ser parte de $s u$ responsabilidad", ${ }^{14}$ lo que conllevaría a mejorar la eficacia de un sistema de seguridad colectiva digno de crédito.

En la segunda parte del informe, el grupo hizo un análisis de las amenazas y peligros a la paz y seguridad internacionales, incluidas aquellas que no podrían ser solucionadas con el mero uso de la fuerza.

El grupo advirtió además que "cualquier suceso o proceso que cause muertes a gran escala o una reducción masiva en las oportunidades de vida y que socave el papel del Estado como unidad básica del sistema internacional constituye una amenaza a la seguridad internacional". ${ }^{15}$ En ese sentido, se dividió en seis grupos ${ }^{16}$ las amenazas que deben preocupar al mundo:

- Las amenazas económicas y sociales, como la pobreza, las enfermedades infecciosas y la degradación ambiental.

- Los conflictos entre Estados.

- Los conflictos internos, como la guerra civil, el genocidio y otras atrocidades a gran escala.

- Las armas nucleares, radiológicas, químicas y biológicas.

- El terrorismo.

- La delincuencia organizada transnacional.

Finalizando la segunda parte, el grupo analiza el papel de las sanciones, advirtiendo que éstas son una herramienta vital, aunque imperfecta, para hacer frente preventivamente a las amenazas a la paz y la seguridad internacionales. ${ }^{17}$

14 Ibidem, párr. 34.

15 Ibidem, p. 27.

16 Idem.

17 UN. Doc. A/59/565..., cit., nota 12, párr. 178. 
En la tercera parte del informe, titulada "La seguridad colectiva y el uso de la fuerza", el grupo se planteó qué ocurre si fracasa la prevención por medios pacíficos, si ninguna de las medidas preventivas que se han descrito hasta ahora detienen el descenso hacia la guerra y el caos, si las amenazas distantes se hacen inminentes, si las amenazas inminentes se hacen reales o si una amenaza no inminente cobra carácter muy real y no parece posible detenerla sin usar la fuerza militar. ${ }^{18}$

En ese contexto, "es necesario distinguir entre las situaciones en que un Estado aduce actuar en legítima defensa, aquellas en que un Estado supone una amenaza para otros más allá de sus fronteras y aquellas en que la amenaza es predominantemente interna y la cuestión reside en la responsabilidad de proteger a la población de un Estado". ${ }^{19}$

Más adelante, todavía en la tercera parte del informe, analizando la legalidad del uso de la fuerza en el marco del capítulo VII de la carta de las Naciones Unidas, el grupo evidencia su apego claro y decidido a la "responsabilidad de proteger" de la siguiente manera:

Los sucesivos desastres humanitarios que han tenido lugar en Somalia, Bosnia y Herzegovina, Rwanda y Kosovo y ahora en Darfur (Sudán) han hecho que la atención se centre no en la inmunidad de los gobiernos soberanos sino en sus obligaciones, tanto respecto de su propio pueblo como de la comunidad internacional en general. Existe un reconocimiento cada vez mayor de que el problema no es el "derecho de intervenir" de un Estado sino la "obligación de proteger" que tienen todos los Estados cuando se trata de seres humanos que sufren una catástrofe que se puede evitar, ya se trate de homicidios o violaciones en masa, de la depuración étnica mediante el terror y la expulsión por la fuerza, de matarlos deliberadamente de hambre o de exponerlos a enfermedades. Está cada vez más aceptado por otra parte que si bien incumbe a los gobiernos soberanos la responsabilidad primordial de proteger a sus propios ciudadanos de catástrofes de esa índole, cuando no pueden o no quieren hacerlo es la comunidad internacional en general la que debe asumir esa responsabilidad [enfatizado por nosotros], que comprende un proceso que va de la prevención y la respuesta a la violencia de ser necesaria a la reconstrucción de sociedades devastadas. Lo primordial debe ser ayudar a que se ponga término a la violencia, sea por conducto de la mediación o de otro mecanismo, y proteger a la población con medidas tales como el envío de misiones humanitarias, 
de derechos humanos o de policía. La fuerza, si hay que usarla, debe constituir un último recurso. ${ }^{20}$

Por otro lado, en el párrafo 203 del informe, el grupo indica que:

Aprobamos la norma que se está imponiendo en el sentido de que existe una responsabilidad internacional colectiva de proteger [enfatizado por nosotros], que el Consejo de Seguridad puede ejercer autorizando la intervención militar como último recurso en caso de genocidio y otras matanzas en gran escala, de depuración étnica o de graves infracciones del derecho internacional humanitario que un gobierno soberano no haya podido o no haya querido prevenir.

A pesar de la importancia sustancial de este párrafo citado, a algunos autores les parece insuficiente ya que el Grupo de Alto Nivel no hace propuestas para incorporar el principio de su regulación en la Carta de las Naciones Unidas. ${ }^{21}$

La tercera parte del informe finaliza estudiando la manera cómo fortalecer la capacidad de las Naciones Unidas para imponer, mantener y consolidar la paz.

Finalmente, en la cuarta y última parte del informe, titulada "Unas Naciones Unidas más eficaces para el siglo XXI", el Grupo de Alto Nivel formula propuestas para un mejor manejo de la organización, incluyendo sugerencias de modificación de los artículos 23, 53 y 107 de la Carta de las Naciones Unidas.

2. Informe del secretario general de las Naciones Unidas. Un Concepto más Amplio de la Libertad: Desarrollo, Seguridad y Derechos

Humanos para Todos (21 de marzo de 2005)

En marzo de 2005, el secretario general de las Naciones Unidas presentó a la Asamblea General su informe titulado Un Concepto más Amplio de la Libertad: Desarrollo, Seguridad y Derechos Humanos para

20 UN. Doc. A/59/565..., cit., nota 12, párr. 201.

21 En ese sentido, véase Sanjosé Gil, Amparo, "Algunas reflexiones sobre el Informe del Grupo de Alto Nivel creado por el secretario general y el futuro del sistema de seguridad colectiva de las Naciones Unidas", Revista Electrónica de Estudios Internacionales, núm. 9, 2005, p. 18, http://www.reei.org/reei9/A.Sanjose(reei9).pdf. 
$\operatorname{Todos}^{22}$ sobre la aplicación de los resultados de la Cumbre del Milenio, ${ }^{23}$ como preparación para la Cumbre Mundial de 2005.

En este informe, el secretario general hace suyas las recomendaciones presentadas en el informe del Grupo de Alto Nivel sobre las Amenazas, los Desafíos y el Cambio, ${ }^{24}$ sin embargo matiza o reforma algunas.

En la introducción del informe, titulada " 2005 , Una oportunidad histórica", el secretario general expresa que aprovechando la Cumbre Mundial 2005 que examinará los progresos realizados desde que se proclamó la Declaración del Milenio de las Naciones Unidas, los dirigentes mundiales pueden tomar decisiones que conlleven a:

Reducir a la mitad la pobreza en el mundo y frenar la propagación de las principales enfermedades conocidas, reducir la prevalencia de los conflictos violentos y del terrorismo. Fortalecer el respeto de la dignidad humana en todos los países. Crear instituciones internacionales más modernas para ayudar a la humanidad a alcanzar esos nobles objetivos. Actuando con audacia - y actuando juntos - podemos hacer que en todas partes los seres humanos estén más seguros, sean más prósperos y tengan mejores posibilidades de gozar de sus derechos humanos fundamentales. ${ }^{25}$

En la segunda parte del informe, titulada "Libertad para vivir sin miseria", el secretario general se ocupa de los temas del desarrollo y la cooperación internacional. Sugiere además que:

Corresponde a cada país en desarrollo la responsabilidad primordial de su propio desarrollo: fortalecer la buena gobernanza, luchar contra la corrupción y adoptar políticas y hacer inversiones que permitan un crecimiento impulsado por el sector privado y aumenten al máximo la disponibilidad de recursos internos para financiar estrategias nacionales de desarrollo.

22 UN. Doc. A/59/2005, Un Concepto más Amplio de la Libertad: Desarrollo, Seguridad y Derechos Humanos para Todos, Informe del secretario general, Quincuagésimo Noveno Periodo de Sesiones, temas 45 y 55: Aplicación y Seguimiento Integrados y Coordinados de los Resultados de las Grandes Conferencias y Cumbres de las Naciones Unidas en las Esferas Económica y Social y Esferas Conexas; y Seguimiento de los Resultados de la Cumbre del Milenio, 21 de marzo de 2005.

23 UN. Doc. A/59/282, Aplicación de la Declaración del Milenio, Informe del secretario general, Quincuagésimo Noveno Periodo de Sesiones, tema 56: Seguimiento de los Resultados de la Cumbre del Milenio, 27 de agosto de 2004.

24 UN. Doc. A/59/565..., cit., nota 12, párr. 147.

25 UN. Doc. A/59/2005, nota 22, párr. 1. 
Por su parte, los países desarrollados se comprometen a actuar de manera que los países en desarrollo que adopten estrategias de desarrollo transparentes, fidedignas y adecuadamente valoradas reciban todo el apoyo que necesitan, en forma de más asistencia para el desarrollo, un sistema de comercio más orientado al desarrollo y la ampliación e intensificación del alivio de la deuda. ${ }^{26}$

En la tercera parte, titulada "Libertad para vivir sin temor", el informe analiza el tema de la seguridad internacional. Propone, además, la creación de la Comisión de Consolidación de la Paz cuyas funciones serían:

Inmediatamente después de acabada una guerra, mejorar la planificación de las Naciones Unidas para lograr una recuperación sostenida, centrándose al principio en establecer las instituciones necesarias; ayudar a conseguir una financiación previsible de las primeras actividades de recuperación, en parte proponiendo distintos mecanismos posibles de financiación basados en cuotas, de carácter voluntario y permanente; mejorar la coordinación de las múltiples actividades que desarrollan los fondos, programas y organismos de las Naciones Unidas después de los conflictos; proporcionar un foro en el que las Naciones Unidas, los principales donantes bilaterales, los países que aportan contingentes, las entidades y organizaciones regionales pertinentes, las instituciones financieras internacionales y el gobierno nacional o de transición del país interesado puedan compartir información acerca de sus respectivas estrategias de recuperación después de un conflicto a fin de lograr una mayor coherencia; examinar periódicamente los progresos realizados en el logro de los objetivos de la recuperación a plazo medio, y mantener la atención política en la fase de recuperación después de un conflicto. ${ }^{27}$

La cuarta parte del informe, titulada "Libertad para vivir en dignidad", el secretario general reflexiona sobre la promoción y la protección de los derechos humanos. Indica además que se debe avanzar hacia la meta de asumir la "responsabilidad de proteger" a las víctimas posibles o reales de atrocidades masivas y actuar en consecuencia. ${ }^{28}$ 
Asimismo, el secretario general reconoce la existencia de una responsabilidad internacional colectiva de proteger:

La CIISE y, más recientemente, el Grupo de Alto Nivel sobre las Amenazas, los Desafíos y el Cambio, cuyos 16 miembros proceden de todas partes del mundo, aprobaron lo que denominaron "la norma que se está imponiendo en el sentido de que existe una responsabilidad internacional colectiva de proteger" (véase A/59/565, párr. 203). Aunque soy bien consciente de lo delicado de la cuestión, concuerdo totalmente con ese punto de vista. Debemos asumir la responsabilidad de proteger y, cuando sea necesario, debemos actuar en consecuencia [enfatizado por nosotros]. Esa responsabilidad recae, primordialmente, en cada Estado, cuya principal razón de ser y obligación es proteger a su población. Pero si las autoridades nacionales no están dispuestas a proteger a sus ciudadanos o no pueden hacerlo, se traslada a la comunidad internacional la responsabilidad de utilizar medios diplomáticos, humanitarios y de otro tipo para ayudar a proteger los derechos humanos y el bienestar de la población civil. Cuando esos métodos parecen ser insuficientes, el Consejo de Seguridad, puede si lo exigen las circunstancias, decidir adoptar medidas al amparo de la Carta de las Naciones Unidas, incluso, si es necesario, medidas coercitivas. En ese caso, como en otros, debe guiarse por los principios enunciados en la sección III supra. ${ }^{29}$

En la quinta parte del informe se plantean medidas para el "fortalecimiento de las Naciones Unidas". Plantea la eliminación del Consejo de Administración Fiduciaria ${ }^{30}$ y la creación de un Consejo de Derechos Humanos $^{31}$ de carácter permanente que reemplace a la Comisión de Derechos Humanos existente.

Finalmente, el secretario general propone a los jefes de Estado y de gobierno una serie de medidas destinadas a mejorar significativamente las condiciones de vida en todo el planeta, incluyendo temas que van desde el uso de la fuerza y la promoción de los derechos humanos hasta la pobreza.

Para ello, insta a los jefes de Estado y de gobierno pedir "al Consejo de Seguridad que apruebe una resolución sobre el uso de la fuerza en la 
que establezca principios que lo regulen y exprese su intención de regirse por ellos al decidir si ha de autorizar o prescribir el uso de la fuerza". ${ }^{32}$

La importancia de este informe, en el aspecto de seguridad internacional, radica en la adhesión a algunos planteamientos de la CIISE, sin embargo se plantea también que "el desarrollo, la seguridad y los derechos humanos van de la mano". 33

\section{Documento final de la Cumbre Mundial 2005}

Los dirigentes del mundo, reunidos en una reunión plenaria de alto nivel denominada Cumbre Mundial 2005, en la Sede de las Naciones Unidas en Nueva York del 14 al 16 de septiembre, acordaron adoptar medidas sobre varios desafíos mundiales, entre ellos, el desarrollo, el terrorismo, la consolidación, mantenimiento y establecimiento de la paz, la responsabilidad de proteger, los derechos humanos, la democracia y el imperio de la ley, la asistencia humanitaria y la actualización de la Carta de las Naciones Unidas, entre otros temas.

Con relación a la responsabilidad de proteger a las poblaciones del genocidio, los crímenes de guerra, la depuración étnica y los crímenes de lesa humanidad, el Acta Final de la Cumbre Mundial 2005 señala que:

Cada Estado es responsable de proteger a su población del genocidio, los crímenes de guerra, la depuración étnica y los crímenes de lesa humanidad. Esa responsabilidad conlleva la prevención de dichos crímenes, incluida la incitación a su comisión, mediante la adopción de las medidas apropiadas y necesarias. Aceptamos esa responsabilidad y convenimos en obrar en consecuencia. La comunidad internacional debe, según proceda, alentar y ayudar a los Estados a ejercer esa responsabilidad y ayudar a las Naciones Unidas a establecer una capacidad de alerta temprana. ${ }^{34}$

Apunta además que:

La comunidad internacional, por medio de las Naciones Unidas, tiene también la responsabilidad de utilizar los medios diplomáticos, humanitarios y

32 Ibidem, anexo, apartado II, 6, h), p. 64.

33 UN. Doc. A/59/2005, nota 22, párr. 14.

34 UN Doc. A/RES/60/1, Documento Final de la Cumbre Mundial 2005, Sexagésimo Periodo de Sesiones, temas 46 y 120 del programa, 24 de octubre de 2005, párr. 138. 
otros medios pacíficos apropiados, de conformidad con los capítulos VI y VIII de la carta, para ayudar a proteger a las poblaciones del genocidio, los crímenes de guerra, la depuración étnica y los crímenes de lesa humanidad. En este contexto, estamos dispuestos a adoptar medidas colectivas, de manera oportuna y decisiva, por medio del Consejo de Seguridad, de conformidad con la carta, incluido su capítulo VII, en cada caso concreto y en colaboración con las organizaciones regionales pertinentes cuando proceda, si los medios pacíficos resultan inadecuados y es evidente que las autoridades nacionales no protegen a su población del genocidio, los crímenes de guerra, la depuración étnica y los crímenes de lesa humanidad. Destacamos la necesidad de que la Asamblea General siga examinando la responsabilidad de proteger a las poblaciones del genocidio, los crímenes de guerra, la depuración étnica y los crímenes de lesa humanidad, así como sus consecuencias, teniendo en cuenta los principios de la carta y el derecho internacional. También tenemos intención de comprometernos, cuando sea necesario y apropiado, a ayudar a los Estados a crear capacidad para proteger a su población del genocidio, los crímenes de guerra, la depuración étnica y los crímenes de lesa humanidad, y a prestar asistencia a los que se encuentren en situaciones de tensión antes de que estallen las crisis y los conflictos..$^{35}$

La importancia de esta reunión de alto nivel no radicó en lo especial de la fecha, aniversario número 60 de las Naciones Unidas, sino en las decisiones que fueron aprobadas en el acta final como parte de una Resolución de la Asamblea General.

Así, por ejemplo, los Estados se comprometen a tomar con responsabilidad sus obligaciones para con la Carta de la ONU, pero también para con sus propios pobladores. Denota esta resolución la marcada influencia de la CIISE.

En ese sentido, el profesor de relaciones internacionales de la Universidad de Santiago de Compostela, Rafael García, indica que:

La responsabilidad de proteger emerge como el reconocimiento de un nuevo principio, no contemplado hasta ahora por la Carta de las Naciones Unidas, que representa un cambio fundamental en la consideración tradicional de la soberanía de los Estados que pasa a ser concebida como un conjunto de derechos y responsabilidades de los poderes públicos frente a sus ciudadanos, entre los que se encontraría la obligación de proteger a la 
propia población. Sólo cuando esta responsabilidad no sea ejercida y provoque situaciones de extrema gravedad, la comunidad internacional por medio de las Naciones Unidas, deberá asumir la responsabilidad de proteger a esa población civil amenazada a través de todos los medios a su alcance establecidos por la carta, incluido el uso de la fuerza militar. ${ }^{36}$

Finalmente, siguiendo al mismo autor citado podemos afirmar que "dos nuevas dimensiones de la seguridad internacional se abren camino con el resultado del Documento Final de la Cumbre, la responsabilidad de proteger y la seguridad humana". ${ }^{37}$

\section{ASPECTOS DOCTRINALES DE LA "RESPONSABILIDAD DE PROTEGER" A LAS VÍCTIMAS DE LAS VIOLACIONES DEL IUS COGENS}

Líneas atrás hemos revisado cómo surge la idea de la "responsabilidad de proteger" a las víctimas de las violaciones del ius cogens. Ahora analizaremos cuáles son los principales aspectos doctrinales de este novedoso planteamiento.

\section{Diferencias doctrinarias entre la "obligación de proteger" y la "responsabilidad de proteger" a las víctimas de las violaciones del ius cogens}

En principio, la "obligación de proteger" es un término que engloba un supuesto derecho a intervenir tanto en términos militares como de otra índole, pero que no va más allá de la mera intervención, no busca una solución permanente a un problema.

En cambio la "responsabilidad de proteger" va más allá de la mera intervención o la responsabilidad de reaccionar ante una catástrofe humana real o previsible, sino que abarca también la responsabilidad de prevenir la catástrofe y de reconstruir después de ella. Estos son los elementos de la responsabilidad de proteger que estudiaremos más adelante.

36 García Pérez, Rafael, 'La 'responsabilidad de proteger': un nuevo papel para Naciones Unidas en la gestión de la seguridad internacional", Revista Electrónica de Estudios Internacionales, núm. 11, 2006, p. 13. http://www.reei.org/reei\%2011/R.Gar ciaPerez(reeil1).pdf.

37 Idem. 


\section{Diferencias doctrinarias entre la "intervención humanitaria" y la "responsabilidad de proteger" a las víctimas de las violaciones del ius cogens}

La "intervención humanitaria" es un término genérico que puede ser utilizado como excusa para una intervención militar cuyos fines no impliquen necesariamente la protección humana.

Por otro lado, no es nuestro propósito, ni de los que plantearon la doctrina de la "responsabilidad de proteger", militarizar la palabra "humanitario".

Sobre el uso de la expresión "intervención humanitaria" la posición del Comité Internacional de la Cruz Roja es la siguiente:

Desde el punto de vista del derecho internacional humanitario, existe una contradicción inmanente cuando se habla de "intervención" o "injerencia" "humanitarias", pues el término "humanitario" debe reservarse a la acción encaminada a mitigar el sufrimiento de las víctimas. Ahora bien, la "intervención humanitaria", tal como se entiende hoy es una intervención armada que implica a menudo un programa político... Así pues, convendría hablar más bien de "intervención armada en repuesta a violaciones graves de los derechos humanos y del derecho internacional humanitario". Tal denominación pondría además de relieve el hecho de que las fuerzas de intervención estarán sometidas al derecho humanitario en sus operaciones militares. $^{38}$

En ese sentido, el informe de la CIISE señala que la comisión ha preferido prescindir del término "intervención humanitaria" y sustituirlo por "intervención" o, cuando proceda, "intervención militar", con fines de protección humana, respondiendo a la oposición manifestada por organismos y trabajadores humanitarios a cualquier militarización de la palabra "humanitario". 39

Los términos que tradicionalmente han sido utilizados en el debate sobre la soberanía y la intervención son: "derecho a la intervención hu-

38 Ryniker, Anne, "La posición del CICR sobre la intervención humanitaria", Comité Internacional de la Cruz Roja, 1o. de marzo de 2001, http://www.icrc.org/Web/ spa/sitespa0.nsf/html/5TDPG6.

39 CIISE, La Responsabilidad de Proteger, Informe de la CIISE, diciembre de 2001, p. 10. http://www.iciss.ca/pdf/Spanish-report.pdf. 
manitaria" o "derecho a intervenir", sin embargo, para la CIISE resultan inadecuados por las siguientes razones: 40

a) Centran necesariamente la atención en las reivindicaciones, los derechos y las prerrogativas de los posibles Estados participantes en la intervención y no en las urgentes necesidades de los posibles beneficiarios de la acción.

b) Al limitarse al acto de intervención, esta formulación tradicional no tiene debidamente en cuenta que es preciso emprender iniciativas preventivas o de asistencia después de la intervención, dos aspectos que con demasiada frecuencia se han pasado por alto en la práctica.

c) Sitúa a la intervención por encima de la soberanía desde el inicio del debate: concede ventaja a la intervención antes siquiera de que comience la discusión, pues tiende a deslegitimar cualquier disensión tildándola de antihumanitaria.

Por estas razones, la CIISE estimó que el debate sobre la intervención con fines de protección humana no debe centrarse en "el derecho a intervenir" sino en "la responsabilidad de proteger". Este cambio terminológico supone una nueva perspectiva: ${ }^{41}$

a) La responsabilidad de proteger implica evaluar los problemas desde el punto de vista de los que piden o necesitan apoyo y no de los que consideran la posibilidad de intervenir.

b) La responsabilidad de proteger presupone que la responsabilidad principal a este respecto corresponde al Estado interesado y que sólo si ese Estado no puede o no quiere cumplirla, o si él mismo es el culpable, incumbirá a la comunidad internacional actuar en su lugar. En muchos casos, el Estado tratará de cumplir con su responsabilidad colaborando plena y activamente con representantes de la comunidad internacional. Así, la "responsabilidad de proteger" es más bien un concepto que sirve para salvar la diferencia entre intervención y soberanía, mientras que la expresión "derecho o deber de intervenir" tiene intrínsecamente un matiz más claro de confrontación.

c) En tercer lugar, la responsabilidad de proteger no significa únicamente "responsabilidad de reaccionar," sino también "responsabilidad de prevenir" y "responsabilidad de reconstruir". Este concepto hace hincapié en el precio y el resultado de la acción frente a la inacción y establece 
vínculos conceptuales, normativos y operacionales entre la asistencia, la intervención y la reconstrucción.

\section{La soberanía frente a la "responsabilidad de proteger" a las víctimas de las violaciones del ius cogens. Un enfoque desde la "seguridad humana"}

Para la CIISE, la soberanía debe concebirse como responsabilidad. En tal sentido, entender soberanía como responsabilidad es importante por tres motivos: 42

a) Implica que las autoridades estatales son responsables de proteger la seguridad y la vida de los ciudadanos y promover su bienestar.

b) Sugiere que las autoridades políticas nacionales son responsables ante los ciudadanos a nivel interno y ante la comunidad internacional a través de las Naciones Unidas.

c) Significa que los agentes del Estado son responsables de sus actos, es decir, que han de rendir cuentas de sus actos u omisiones. Este concepto de soberanía está respaldado por la creciente influencia de las normas de derechos humanos y la mayor presencia en el discurso internacional del concepto de "seguridad humana". ${ }^{43}$

Contemporáneamente, el sentido y el alcance del concepto de seguridad se han ampliado. A tal respecto, la CIISE acepta "que las cuestiones relativas a la soberanía y la intervención no afectan únicamente a los derechos o prerrogativas de los Estados, sino que tienen una profunda y fundamental repercusión en cada ser humano". ${ }^{4}$

Con este enfoque, el eje en torno al que gira el debate sobre la seguridad se desplaza desde la seguridad territorial y la seguridad basada en el armamento hacia la seguridad basada en el desarrollo humano y el acceso a la alimentación, el empleo y la seguridad ambiental. Los componentes básicos de la seguridad humana - la seguridad de las personas frente a las amenazas contra la vida, la salud, los medios de subsistencia, la seguridad personal y la dignidad humana - pueden verse en peligro debido a una

42 Ibidem, p. 14.

43 La seguridad humana abarca la seguridad de las personas, su seguridad física, su bienestar económico y social, el respeto a su dignidad y valía como seres humanos y la protección de sus derechos humanos y libertades fundamentales. Véase ibidem, p. 15.

44 Idem. 
agresión externa pero también a factores internos, incluidas las fuerzas de "seguridad" de un país concreto... Esta limitada concepción tradicional de la seguridad... hace que se destinen enormes cantidades de recursos nacionales, tanto materiales como humanos, a los armamentos y las fuerzas armadas, mientras los países dejan de proteger a sus ciudadanos de la inseguridad crónica generada por el hambre, las enfermedades, las viviendas inadecuadas, la delincuencia, el desempleo, los conflictos sociales y los peligros ambientales. Cuando se utiliza la violación como instrumento de guerra y depuración étnica, cuando miles de personas mueren a causa de las inundaciones provocadas por la destrucción del terreno y cuando los ciudadanos son asesinados por sus propios cuerpos de seguridad, ya no basta con considerar la seguridad en términos de seguridad nacional o territorial. El concepto de seguridad humana puede y debe abarcar todas esas circunstancias. $^{45}$

En ese sentido, observamos que la doctrina de la seguridad humana es totalizadora, ya que incluye todos los aspectos que el ser humano necesita para satisfacer su seguridad no sólo individual sino colectiva, física, mental o social, incluido su "desarrollo humano". ${ }_{46}$

Recordemos que la noción de seguridad humana fue definida por primera vez en el Informe sobre Desarrollo Humano del Programa de las Naciones Unidas para el Desarrollo (PNUD) de 1994, en donde se expuso que "la seguridad humana no es una preocupación por las armas: es una preocupación por la vida y la dignidad humanas". ${ }^{47}$ Asimismo, el informe indicó que:

45 Ibidem, pp. 15 y 16.

46 El desarrollo humano es un proceso en el cual se amplían las oportunidades del ser humano... las tres más esenciales son disfrutar de una vida prolongada y saludable, adquirir conocimientos y tener acceso a los recursos necesarios para lograr un nivel de vida decente. Si no se poseen estas oportunidades esenciales, muchas otras alternativas continuarán siendo inaccesibles... Otras oportunidades... van desde la libertad política, económica y social, hasta la posibilidad de ser creativo y productivo, respetarse a sí mismo y disfrutar de la garantía de derechos humanos. El desarrollo humano tiene dos aspectos. Véase United Nations Development Programme, Human Development Report 1990. Concept and Measurement of Human Development, Nueva York-Oxford, Oxford University Press, 1990, p. 34.

47 United Nations Development Programme, Human Development Report 1994. Concept and Measurement of Human Development, Nueva York-Oxford, Oxford University Press, 1994, p. 25. 
La seguridad humana tiene dos aspectos principales. En primer lugar, significa seguridad contra amenazas crónicas como el hambre, la enfermedad y la represión. $\mathrm{Y}$ en segundo lugar, significa protección contra alteraciones súbitas y dolorosas de la vida cotidiana, ya sea en el hogar, en el empleo o en la comunidad. Dichas amenazas pueden existir en todos los niveles de ingreso y desarrollo de un país. ${ }^{48}$

Entonces, la seguridad humana tiene muchas facetas que sobrepasan lo meramente militar. El ser humano, en su vida cotidiana, tiene que enfrentar una serie de amenazas, que el informe citado trató de organizar en siete categorías principales: seguridad económica, alimentaria, de salud, ambiental, personal, de la comunidad y seguridad política.

Como consecuencia de este informe, muchos Estados, encabezados por Canadá, han incluido el tema de la seguridad humana en sus agendas de política exterior. Sin embargo, no existe consenso sobre la conceptualización del término. Prueba de ello es la creación de la Red de Seguridad Humana, ${ }^{49}$ que surgió durante la campaña sobre minas terrestres y que fue lanzada oficialmente durante una reunión ministerial en Noruega en 1999.

En la Red de Seguridad Humana ${ }^{50}$ se mantiene un diálogo sobre cuestiones vinculadas a la seguridad humana al nivel de ministros de Asuntos Exteriores.

Por iniciativa del gobierno de Japón, en enero de 2001, se crea la Comisión de Seguridad Humana ${ }^{51}$ cuyo informe fue entregado a Kofi

\section{Idem.}

49 La Red de Seguridad Humana tiene el objetivo de dinamizar los procesos políticos destinados a prevenir y resolver los conflictos y promover la paz y el desarrollo. La red promueve la universalización de la Convención de Ottawa, el establecimiento de la Corte Penal Internacional, la protección de los niños durante conflictos armados, el control de las armas pequeñas y ligeras, la lucha contra el crimen organizado internacional, el desarrollo humano y la seguridad humana, los Derechos Humanos educativos, la lucha contra el virus HIV-SIDA. Véase http://www.humansecuritynetwork. org/network-s.php.

50 Está conformada por Australia, Canadá, Chile, Costa Rica, Grecia, Irlanda, Jordania, Mali, Países Bajos, Noruega, Suiza, Eslovenia, Tailandia y Sudáfrica como observadores.

51 Creada en respuesta al llamado del secretario general de la ONU en la Cumbre del Milenio (2000). Conformada por 12 connotadas figuras internacionales, incluyendo a la señora Sadako Ogata (ex alto comisario para Refugiados de la ONU) y el profesor 
Annan el 1o. de mayo de 2003. El informe coincide con varias apreciaciones e iniciativas anteriores y hace una serie de propuestas sobre la seguridad humana.

Aunque algunos autores afirman que el concepto de seguridad humana es ambiguo ya que existen muchas variaciones, ${ }^{52}$ nosotros pensamos que este nuevo concepto se consolidará con el transcurrir de los años.

A modo de conclusión podríamos decir que la soberanía tiene un carácter dual, que implica tanto derechos como responsabilidades. Entre las responsabilidades primordiales de los Estados se encuentran la de proteger a su población, pero si éste no quiere o no puede protegerla, la responsabilidad se deriva a la comunidad internacional encabezada por las Naciones Unidas.

\section{FUNDAMENTOS JURÍDICOS DE LA "RESPONSABILIDAD \\ DE PROTEGER" A LAS VÍCTIMAS DE LAS VIOLACIONES DEL IUS COGENS}

Para la CIISE, los fundamentos de la "responsabilidad de proteger", como principio rector de la comunidad internacional de Estados, radican en: ${ }^{53}$

a) Las obligaciones inherentes al concepto de soberanía.

b) El artículo 24 de la Carta de las Naciones Unidas que confiere al Consejo de Seguridad la responsabilidad de mantener la paz y la seguridad internacionales.

c) Las obligaciones jurídicas específicas que dimanan de las declaraciones, los pactos y los tratados relativos a los derechos humanos y la protección humana, así como del derecho internacional humanitario y el derecho interno.

Amartya Sen (laureado Nobel de Economía de 1998). Véase http://www.humansecu rity-chs.org/.

52 Leal Moya, Leticia, "Seguridad humana. La responsabilidad de proteger", Boletín Mexicano de Derecho Comparado, nueva serie, año XXXVIII, núm. 114, septiembre-diciembre de 2005, p. 1128. En ese mismo sentido, véase King, Gary y Murray, Christopher J. L., "Rethinking Human Security", Political Science Quarterly, vol. 116, núm. 4, 2001-2002, pp. 591 y 592, citado por Leal Moya, Leticia, op. cit., en esta misma nota, p. 1128.

53 CIISE, La Responsabilidad..., cit., nota 39, p. X. 
d) La práctica creciente de los Estados, las organizaciones regionales y el propio Consejo de Seguridad.

Creemos que la responsabilidad de proteger importa al Estado, que la ostenta frente a cualquier persona bajo su jurisdicción (incluyendo territorios administrados por ocupación beligerante u otra índole). Subsidiariamente, a la ONU le corresponde asumir dicha responsabilidad en casos específicos.

\section{ELEMENTOS DE LA "RESPONSABILIDAD DE PROTEGER" A LAS VÍCTIMAS DE LAS VIOLACIONES DEL IUS COGENS}

\section{La responsabilidad de prevenir}

Consiste en eliminar tanto las causas profundas (como la pobreza) y las causas directas (o desencadenantes) de los conflictos internos y otras crisis provocadas por el hombre que pongan en peligro a la población.

Así, la prevención de causas profundas tiene varias dimensiones desde políticas (como creación de instituciones democráticas), económicas (como resolver la falta de oportunidades) hasta jurídicas (como el fortalecimiento de instituciones jurídicas), incluida la reforma del ejército y otros cuerpos de seguridad del Estado. ${ }^{54}$

Por otro lado, la prevención de las causas directas consta de los mismos componentes, pero la diferencia es que se dispone de menos tiempo para actuar. Por ello, las medidas políticas y diplomáticas pueden incluir la intervención del secretario general de la ONU. Las medidas económicas de prevención directa pueden ser positivas (como la promesa de fondos, inversiones o intercambio favorable) y negativas o coercitivas (como amenaza de sanciones económicas). ${ }^{55}$

\section{La responsabilidad de reaccionar}

Cuando la prevención no surte efectos y un Estado no puede o no quiere solucionar el conflicto, la comunidad internacional puede interve- 
nir mediante medidas coercitivas de carácter político, económico, judicial y sólo en casos extremos intervendrá militarmente. ${ }^{56}$

La responsabilidad de reaccionar consiste en responder ante situaciones en que exista una imperiosa necesidad de protección humana, a través de medidas adecuadas, que pueden incluir medidas coercitivas o legales en el plano internacional, y en casos extremos la intervención militar que implique el cumplimiento de unos estrictos requisitos.

\section{La responsabilidad de reconstruir}

Luego de la intervención militar, se debe ayudar a consolidar una paz duradera, promover la gobernanza y el desarrollo sostenible. Las fuerzas de intervención deben ofrecer seguridad y protección a la población sin discriminación. Adicionalmente, se debe hacer frente al problema de la justicia, la reconciliación y el problema de los refugiados. ${ }^{57}$

En otras palabras, la responsabilidad de reconstruir consiste en ofrecer, posteriormente a la intervención militar, asistencia para la recuperación, la reconstrucción y la reconciliación, eliminando las causas del daño que la intervención pretendía atajar o evitar, es decir, tratar de consolidar la paz.

\section{LOS RESPONSABLES DE PROTEGER A LAS VÍCTIMAS DE LAS VIOLACIONES DEL IUS COGENS}

\section{El Estado}

El Estado es el responsable primordial de proteger a su propia población de amenazas de toda índole. Esta responsabilidad se deriva de su propia soberanía. Sin embargo, en caso que un Estado no quiera o no pueda proteger a su población que sufre masivas violaciones de sus derechos humanos, cualquier otro Estado podría asumir dicha responsabilidad de conformidad con la Carta de las Naciones Unidas y el derecho internacional vigente. 


\section{La comunidad internacional}

A pesar de que "comunidad internacional" es un término ambiguo, creemos conveniente incluirlo para denotar que son todos los Estados los que también tiene la responsabilidad de proteger a cualquier población que se encuentre en peligro ante violaciones masivas de sus derechos humanos.

\section{Las Naciones Unidas}

La organización más importante del mundo y que por regla tiene la obligación de mantener la paz y la seguridad internacionales también tiene la "responsabilidad de proteger" a través de sus órganos principales: el Consejo de Seguridad y la Asamblea General.

\section{A. Consejo de Seguridad}

Es el Consejo de Seguridad quien por legítimo interés tiene la "responsabilidad de proteger" a los pueblos que sufran violaciones masivas de sus derechos humanos. La Carta de las Naciones Unidas le otorga al consejo atribuciones tales como el mantenimiento de la paz y la seguridad internacionales y puede utilizar todos los medios a su disposición para lograr dichos objetivos.

\section{B. La Asamblea General}

La Asamblea General también tiene la "responsabilidad de proteger", ya que puede discutir cualquier asunto que implique mantener la paz y seguridad internacionales, pero dentro de los límites de la Carta de las Naciones Unidas.

\section{LA "RESPONSABILIDAD DE PROTEGER" \\ A LAS VÍCTIMAS DE LAS VIOLACIONES DEL IUS COGENS \\ Y LA INTERVENCIÓN MILITAR}

Antes de tomar la decisión de intervenir militarmente, se deben utilizar otras medidas coercitivas, sin embargo se debe tener bastante cuidado ya que podrían causar más daño a la población civil. 
En el ámbito militar se puede realizar un embargo de armas y poner fin a cualquier programa de cooperación militar y de entrenamiento. En el ámbito económico las sanciones financieras pueden tener por objetivo los activos externos de las partes involucradas en el conflicto, asimismo, se puede restringir ciertas actividades que generen ingresos o prohibir el tráfico aéreo. ${ }^{58}$

Finalmente, en el ámbito político y diplomático se puede expulsar a los funcionarios de la misión diplomática, restringir viajes a dirigentes y familiares, suspender o expulsar al Estado de una organización internacional o negarle la admisión. ${ }^{59}$

\section{Criterio mínimo: causa justa}

La intervención militar con fines de protección humana es una medida excepcional y extraordinaria. Para que esté justificada ha de existir, o ser inminente, un daño humano grave e irreparable que cumpla al menos una de estas dos condiciones: ${ }^{60}$

a) Grandes pérdidas de vidas humanas, reales o previsibles, con o sin intención genocida, que sean consecuencia de la acción deliberada de un Estado, de su negligencia o incapacidad de actuar o del colapso de un Estado.

b) 'Depuración étnica' a gran escala, real o previsible, llevada a cabo mediante el asesinato, la expulsión forzosa, el terror o la violación.

La CIISE aclara cuáles son las circunstancias que deben estar incluidas en estas dos condiciones: ${ }^{61}$

a) Los actos definidos en el marco de la Convención contra el Genocidio de 1948, que conllevan grandes pérdidas de vidas humanas reales o inminentes;

b) Grandes pérdidas de vidas humanas reales o inminentes, sean o no producto de una intención genocida e impliquen o no la acción de un Estado;

58 Ibidem, p. 34.

59 Ibidem, pp. 34 y 35.

60 Ibidem, pp. 36 y 37.

61 Ibidem, p. 37. 
c) Diferentes tipos de "depuración étnica," como el asesinato sistemático de los miembros de un grupo concreto con el fin de reducir o eliminar su presencia en una zona determinada; el traslado sistemático de los miembros de un grupo concreto fuera de una determinada zona geográfica; los actos de terror encaminados a forzar la huida de ciertas personas; $y$ la violación sistemática de mujeres de un grupo determinado con objetivos políticos (ya sea como otra forma de terrorismo o para modificar la composición étnica de dicho grupo);

d) Los crímenes de lesa humanidad y las infracciones de las leyes de la guerra, tal como se definen en los Convenios de Ginebra y sus protocolos adicionales, así como en otros instrumentos, que conlleven matanzas o depuraciones étnicas en gran escala;

e) El colapso de un Estado, que expone a la población a la inanición masiva o la guerra civil; $y$

f) Las catástrofes naturales o ecológicas de grandes proporciones, a las que el Estado no quiera o no pueda hacer frente ni solicitar asistencia, y que provoquen o puedan provocar importantes pérdidas humanas.

La CIISE opina que, la intervención militar con fines de protección humana debe limitarse exclusivamente a las situaciones en que se produzcan o sean inminentes grandes pérdidas de vidas civiles o depuraciones étnicas. Por lo que, ante otras violaciones de los derechos humanos como la discriminación racial sistemática, el encarcelamiento sistemático u otro tipo de represión de los opositores políticos resultaría conveniente estudiar la posibilidad de imponer sanciones políticas o económicas, ya que, a juicio de la comisión, no justificarían una acción militar con fines de protección humana. ${ }^{62}$

A pesar de los requisitos exhaustivos y las previsiones que se tomen, el problema de las pruebas para la intervención militar es de vital importancia. Para la CIISE el Comité Internacional de la Cruz Roja sería el candidato obvio para presentar las pruebas, sin embargo su neutralidad descarta su actuación.

Sin embargo, los órganos y organismos de las Naciones Unidas, como los altos comisionados para derechos humanos y para los refugiados, preparan informes que podrían ser útiles. No hay que descartar los análisis que llevan a cabo otros organismos internacionales y organizaciones no gubernamentales de prestigio. 
Finalmente, hay que recordar que el artículo 99 de la Carta de las Naciones Unidas confiere al secretario general autoridad suficiente para "llamar la atención del Consejo de Seguridad hacia cualquier asunto que en su opinión pueda poner en peligro el mantenimiento de la paz y la seguridad internacionales".

\section{Principios precautorios}

Según la CIISE para que una situación se considere como "causa justa" de intervención se deben cumplir además otros cuatro principios: ${ }^{63}$

a) Intención correcta: Como el fin primordial de la intervención, independientemente de que los Estados participantes tengan otros motivos, debe ser atajar o evitar el sufrimiento humano. En tal sentido, el principio de intención correcta consiste en que las operaciones sean multilaterales y cuenten con un claro respaldo de las víctimas y de la opinión pública regional.

b) Último recurso: Sólo cuando se hayan intentado todas las demás opciones no militares para prevenir o dar una solución pacífica a la crisis y cuando haya motivos razonables para creer que otras medidas menos enérgicas no habrían dado fruto, la intervención militar puede justificarse.

c) Medios proporcionales: Esto quiere decir que la escala, duración e intensidad de la intervención militar prevista debe ser la mínima necesaria para alcanzar el objetivo de protección humana establecido. Asimismo, se deben respetar íntegramente las normas del derecho internacional humanitario.

d) Posibilidades razonables: Es decir, debe haber una posibilidad razonable de poder atajar o evitar el sufrimiento que ha justificado la intervención, y las consecuencias de la acción no pueden ser peores que las de la inacción. La CIISE advierte que no se podría realizar una acción militar como la descrita contra uno de los cinco miembros permanentes del Consejo de Seguridad aunque cumpliera con los requisitos expuestos. O puede ocurrir que el precio de rescatar a unos cuantos seres humanos sea una conflagración regional.

\section{Autoridad competente}

Para la doctrina de la "responsabilidad de proteger", ${ }^{64}$ es el Consejo de Seguridad quien tiene la responsabilidad primordial de mantener la 
paz y la seguridad internacionales; por tanto, se le debe pedir autorización antes de emprender una intervención militar. El consejo puede plantearla por propia iniciativa o el secretario general la puede plantear de conformidad con el artículo 99 de la Carta de las Naciones Unidas.

Para la CIISE, el Consejo de Seguridad deberá examinar sin demora toda solicitud de autorización para intervenir cuando se denuncien grandes pérdidas de vidas humanas o depuraciones étnicas a gran escala. Asimismo, los cinco miembros permanentes del consejo deberán renunciar de mutuo acuerdo a ejercer su derecho de veto en asuntos que no comprometan sus intereses vitales, para no obstaculizar la aprobación de resoluciones que autoricen una intervención militar con fines de protección humana y que cuenten con apoyo mayoritario.

La CIISE también se puso en el caso que el Consejo de Seguridad rechace una propuesta o no la examine en un periodo de tiempo razonable, brindando las alternativas siguientes:

a) Que la Asamblea General examine la cuestión en un periodo extraordinario de sesiones de emergencia, con arreglo al procedimiento establecido en la resolución "Unión pro Paz".

b) Que una organización regional o subregional, en virtud de lo dispuesto en el capítulo VIII de la carta, actúe dentro de su zona de jurisdicción y posteriormente solicite la autorización del Consejo de Seguridad.

Como podemos observar, la CIISE admite que si el Consejo de Seguridad no cumple con su "responsabilidad de proteger", los Estados interesados podrán recurrir a otros medios para hacer frente a la gravedad y urgencia de la situación, lo que podría menoscabar el prestigio y la credibilidad de las ONU.

Para nosotros, una causa legítima de intervención por razones de protección humana es tal cuando cumple con los fundamentos jurídicos necesarios. Si no existen en el momento mecanismos jurídicos para intervenir, la que pierde legitimidad es la ONU y no la intervención basada en la responsabilidad de proteger.

En el esquema sobre la doctrina de la responsabilidad de proteger (véase en la siguiente página), indicamos los principales aspectos teóricos de ella. Los Estados soberanos tienen la responsabilidad primordial de proteger, las Naciones Unidas la tienen, si los Estados no pueden o no quieren asumirla. 
Esquema. Doctrina de la responsabilidad de proteger

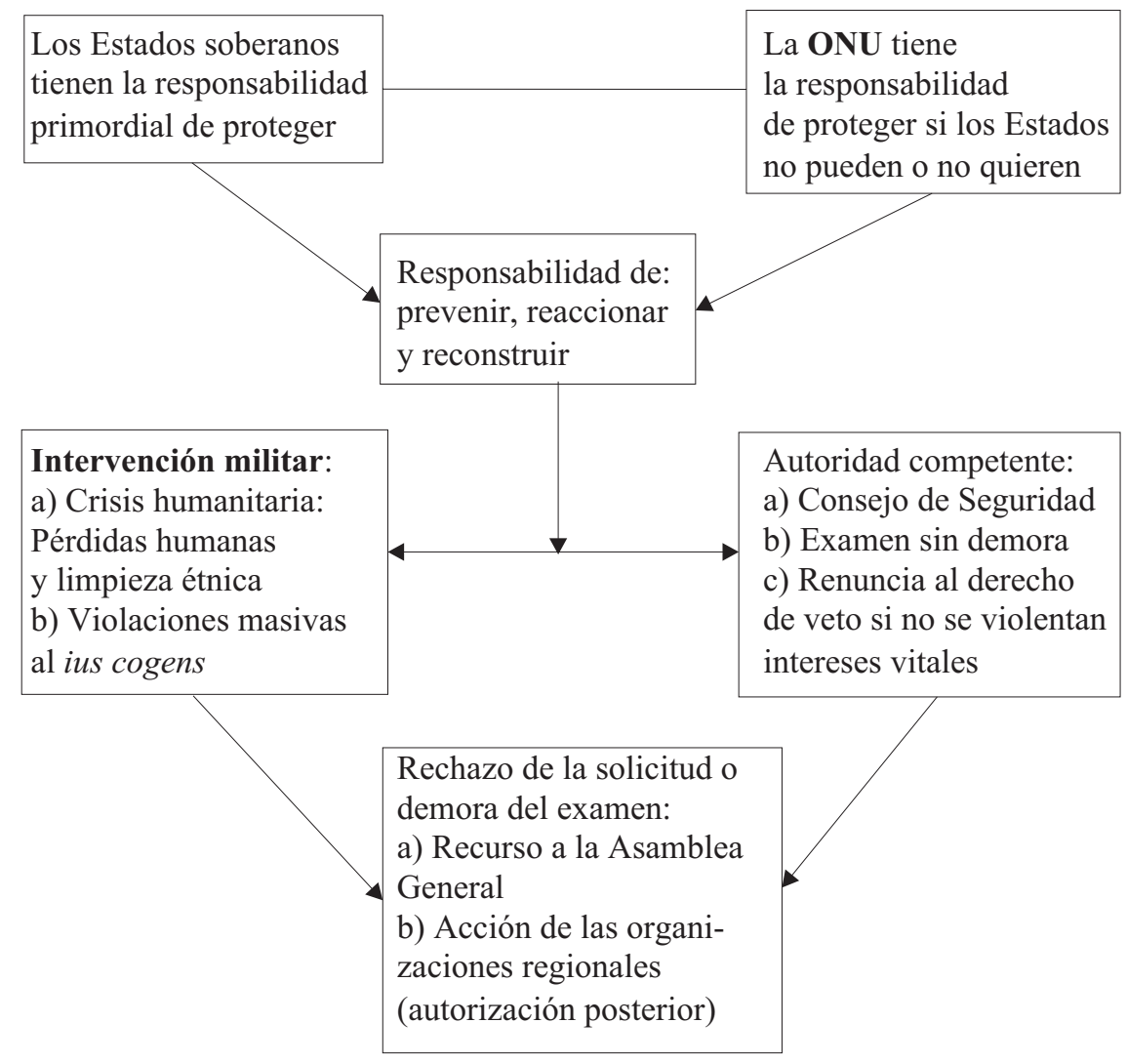

FUENTE: Elaborado por el autor con base en el informe de la CIISE, La Responsabilidad de Proteger, 2001. 
Dicha responsabilidad consiste en prevenir, reaccionar y reconstruir. Sin embargo, cuando en un conflicto se evidencia una grave crisis humanitaria, y las pérdidas humanas y la limpieza étnica son patentes, así como las violaciones masivas al ius cogens, se podría efectuar una intervención militar que debe ser solicitada al Consejo de Seguridad de las Naciones Unidas como autoridad competente, este último debe examinar sin demora el caso, al mismo tiempo que los Estados con derecho a veto renuncian a él, siempre y cuando no se violenten sus intereses vitales.

En el caso extremo de que exista un rechazo de la solicitud o una visible demora del examen en el Consejo de Seguridad, se deberá recurrir a la Asamblea General o a la acción de las organizaciones regionales que pueden solicitar la autorización posterior al Consejo de Seguridad.

\section{CONCLUSIONES}

1. La soberanía tiene carácter dual, que implica tanto derechos como responsabilidades. Entre las responsabilidades primordiales de los Estados se encuentra la de proteger a su población, pero si éste no quiere o no puede protegerla, la responsabilidad se traslada a la comunidad internacional encabezada por las Naciones Unidas.

2. No sólo los Estados ostentan la "responsabilidad de proteger", también la posee el Consejo de Seguridad, que actúa con base en sus competencias que fluyen de la carta. La Asamblea General podría asumir la responsabilidad de proteger en caso que el consejo no actúe por algún motivo. Si las Naciones Unidas no asumen su responsabilidad de proteger a las víctimas de violaciones del ius cogens se desprestigiarán debido a que los Estados podrían recurrir a otros mecanismos ante alguna urgencia o crisis humanitaria.

3. Las organizaciones regionales, actuando dentro de su zona de jurisdicción, podrían hacerse cargo de la responsabilidad de proteger, para luego solicitar autorización al Consejo de Seguridad.

4. Una causa legítima de intervención por razones de protección humana es tal cuando cumple con los fundamentos jurídicos necesarios. Si no existen en el momento mecanismos jurídicos para intervenir, la que pierde legitimidad es la ONU, y no la intervención basada en la responsabilidad de proteger. 